\title{
Socio-cultural trends in Women's Founders Training, Mentorship, Transition and Transformation with a Special Focus on Botswana
}

\author{
Wapula N. Raditloaneng ${ }^{1}$ \\ ${ }^{1}$ Adult and Continuing Education, Faculty of Education, University of Botswana, Gaborone \\ Correspondence: Wapula N. Raditloaneng, Associate professor, Adult and Continuing Education, Faculty of \\ Education, University of Botswana, P/Bag 00702, Gaborone. Tel: 267-55-2066. E-mail: Raditloa@mopipi.ub.bw
}

Received: August 18, 2012 Accepted: October 31, 2012 Online Published: November 9, 2012

doi:10.5539/ells.v2n4p91 URL: http://dx.doi.org/10.5539/ells.v2n4p91

\begin{abstract}
Botswana women have historically played very crucial roles in the Non-Governmental Organizations (NGOs) as great partners and gap fillers in national development. Among the most important aspects of founding NGOs organization is the need to train, mentor and transform, and transit from the organization with no doubt about its autonomy and sustainability.

This article is informed by a Based on a workshop methodology with a total of twenty women from the USA and Botswana women assembled under the auspices of the Women's Affairs Department and have occasional meetings since 2008. A key finding from studying the Women's Founders Collective is that women are socioculturally groomed to participate in unpaid NGO work even if they have been trained, mentored and make an impact enough to transform organizations and communities they serve.

With the advent of the cash economy, the trends of women as key actors in NGOs have changed to include men especially in instances where there are some financial rewards. Regardless of whether key actors are men or female, the need for intensive training, mentorship, transition and transformation can not be overemphasized. This is the gist of the journal article, using women as a point of contact.
\end{abstract}

Keywords: Women's Founders Training, mentorship, transitions, transformation

\section{Introduction}

The focus of this paper is to critically assess the concepts of training, mentorship and transformation as applicable to the Women's Founders as a viable NGO to replicate to the developing countries, based on the focus group discussions with women founders.

The key sessions of the workshop that informed this paper were on 1) Starting an Organisation 2) Managing it and 3) Letting it go. The three concepts of training including mentorship, transition and transformation are included in a critique of the three session workshop with a special focus on Botswana women and how they have dominated the NGO sector where work is mainly for passion and charity rather than gainful paid work.

The ultimate purpose of this paper is to illuminate the problems associated with lack of training, women as leaders, mentorship and transformation of NGO work where women form the majority. Trends in post independence Botswana indicate the great efforts of women founders who worked for free under extreme shortage of human and non human resources. As the NGO movement became global and donors started channeling resources, trends changed and more and more men joined NGO for paid leadership positions.

The author carves the way forward in articulating the need for proper training, mentorship and ensuring that every stakeholder is on board during the transition and transformation period for sustainable development. The author further show-cases the importance of training of all women and men willing to serve as women's/men's founders, to effectively handle their role in leadership with a special focuse on the women's movement in Botswana.

\section{Background}

The Women's Founders Collective is a global network of women who have a passion for promoting training of women in leadership, women's empowerment and building supportive partners who can assist women to grow and take leadership positions in all fronts including NGOs. As a network, the Women's Founders Collective was 
founded by individuals who put their money together to find the organization. The most important aspect of starting the organization was to first find out who is there, and also make efforts to bring and train on board women in rural areas so that the Women's founders collective is not perceived as an urban NGO.

It is against this background that the representatives of the Women's Founders visited Botswana and held a workshop $20^{\text {th }}$ march 2008 to sell the idea of recognizing women as founders of NGOs, empowering those left behind and forming a solid network within which women can be mentored, empowered to engage in transition and transformation of global Women's founders NGOs. The workshop sessions were very dialogic, informal and gave women an opportunity to share their experiences with NGOs and the need to organize a conference that would bring together women from all walks of life. (www.womenfounders.org).

\section{Conceptual Framework}

The conceptual framework that informed this paper is extensively based on gender and a feminist standpoint as lenses for articulating the need for training, mentorship, transition and transformation of both men and women. Approaches that inform this study are the Feminist (post-structuralists, Critical Third World) and the Women's Empowerment approaches. These two approaches are relevant because they provide a gender lens that is useful to analyze women's lack of skills. Feminist and women's empowerment approaches are appropriate for explaining lack of training and mentorship as gender based and women's empowerment problems. Based on the notion that bridging gender gaps and empowering women are indispensable aspects of overall national development, feminist approaches emphasize worldwide equal treatment for both men and women.

\section{The Relevance of Third World Feminist Actors}

The feminist movement in the Third World is the brainchild of the growing awareness of global changes in the roles, functions and status of women. Women's role in the United States, in Botswana and globally, has evolved from household chores to different societal roles; hence women are no longer confined only to household level chores. Women are therefore gradually becoming key players at household and community, national and international levels. Feminist researchers share the assumption that gender inequality and disempowerment disproportionately affect men and women. Some of the representatives relevant for this framework include Bell hooks, Amina Mama, and Caroline Moser who give special recognition to the way disempowerment is associated with inequalities between men and women. hooks (1994), and Tisdell (1993), using a feminist perspective, perceive gender-based oppression and discrimination as the source of inequalities between men and women. Some of the representatives of the empowerment approaches who are also progressive include Freire (1970).

Feminist approaches that inform this article use the lens of gender, sex and sexuality. As mentioned earlier, feminist approaches are sensitive to gender based subordination typified in inequalities between men and women. Gender is a socially constructed definition of the roles of men and women in any society. Gender as a lens defines women as feminine, and men as masculine. Social inequalities have to do with the behavior of men and women. The feminist approach used in this study includes Third World analysts who frame gender roles associated with women's sex (biological) and sexuality (childbearing). These roles influence socio-cultural aspects of training, mentorship, transition and transformation.

Third World Feminists classify women's oppression as threefold; gender, class, and race/ethnic relations (Mbiliyi, 1996). This study is informed by research which identifies gender inequality as the main factor in women's oppression, training, mentorship or lack of it. Given the problems of under presentation of women in decision-making and leadership, socio- cultural norms that discriminate against women, gender, sex and sexuality are the most relevant factors for explaining women in the gender and NGO movement.

Feminist approaches attribute major causes of lack of training, mentorship, transition and transformation for women's founders to inequalities between men and women. These inequalities are socio-cultural and perpetuated by patriarchy.

Historically, women continue to be untrained un-mentored and incapable of meaningful transition because of their subordination to men, especially in employment, love relationships, reproduction and marriage. Structures that oppress women need uprooting by making an effort to address women's issues as Human Rights issues in ways perceived by women.

\section{Feminist Streams}

Feminism is a political struggle to end sexist oppression. One stream of feminists can be traced back to the French Revolution of 1792 which influenced the works of Mary Wollstonecraft who argued that women's capacity to reason was relevant to grant them political rights and equality with men. These feminists see the root 
causes of gender- based inequalities as women's subordination by gendered norms rather than biological sex. They criticize these socio-cultural norms and would like them changed to better the conditions of women, and this would maximize individual happiness and liberty. Social opportunities should be provided equally for men and women so that the best available people fill positions. Educational opportunities, thus raising the literacy levels, should be available for both men and women, and in addition, there should be a repeal of legal discrimination against women (Jaggar and Rothenberg, 1993; Mbiliyi, 1996).

Another stream of feminists are those that are traceable to the late 1960s. They situate women's subordination as primary to all forms of subordination, and as a consequence of gender and sexuality. However, feminists do not agree on the origins and nature of women's subordination. Sex and gender are inseparable because they influence social practices that have a bearing on women's subordination (Jaggar and Rothenberg, 1993). Another steam of feminist actors is radical in orientation.

Stefanos (1996) observes that:

Radical feminists argue that the primary source oppression of women is patriarchal oppression. Radical feminists substitute gender for class, race and nationality as a prime motor in the materialistic account of history. Education is important to the extent that it changes women's consciousness and enables them to be free from men (p. 262).

Gender is the pillar of enquiry about gender- based inequalities because its causes and solutions are rooted in relationships between men and women (Tong, 1989; Mohanty, 1991b). Mama, hooks and others would assert that what is essential for long-term elimination of gender disparities is to design gender transformative policies or even redistribution of resources between men and women.

\section{Limitations of the Feminist Approaches}

Feminist approaches explain lack of training, mentorship, transition and transformation only as they relate to inequalities between men and women, sex and sexuality. This invariably means that the approach is not concerned about socio- cultural disparities not explainable by gender.

Feminists also differ in articulating scope of major factors in gender disparities and requisite actions. This is the main limitation of the way empowerment is practiced. It is not clear how much of the envisioned improvement can be attributed to training, mentorship, transition and transformation.

\section{Socio-cultural Practices}

There are gender-based practices relating to women's sexuality and gender that have constrained women and indirectly have the potential to cause or aggravate lack of training, mentorship, transition and transformation of women in the NGO sectors. Traditional stereotypes, proverbs and laws that have been reproduced over generations have relegated women to the role of active producers with closed mouths. Custom prescribes male supremacy, dominance and leadership while a woman's duty is to follow. As women become more gender aware through workshops and campaigns by NGOs, and as the literacy rate for women improves in Botswana, the feminist movement is emerging to challenge these stereotypes. With the changing role of women, and high levels of literacy and legal awareness, women have continued to question the relevance of these in modern Botswana society.

\section{Inadequacy of the Legal Framework}

The legal framework, like socio-cultural practices, reinforces gender-based disparities (Mannathoko, 1992; Ministry of Finance and Development Planning, 1997; Dow and Kidd, 1994). Enforcement of child support or maintenance laws is also not strict. Women are therefore perceived to be the best in childrearing, giving material and emotional support.

\section{Women's Socialization and Reproduction}

Women's socialization at family, community and household levels aggravate gendered inequalities. Despite evidence from the many female-headed mothers in Botswana that, in love relationships fathers disappear after pregnancy, Batswana women have continued to have children outside marriage. This has constrained their access to participation in civic life, training, mentorship, transition and transformation.

\section{Teenage Pregnancy and the School System}

The Botswana schools system has gender inequalities reflected in treatment of school teenage girls who fall pregnant. Studies carried out by educationists and health research specialists indicate that girls drop out of school 
due to pregnancy. (Chilisa, 1998; Botswana Society, 1997; Nyati-Ramahobo, 1992). Pregnancy therefore places teenage mothers at the risk of not going for further education, training, mentorship, transition and transformation.

\section{The Women's Empowerment Approach}

Like the feminist, the women's empowerment approach explain gender disparities as a collective, multifaceted problem. The higher the level of literacy, the more women are likely to be empowered to go to school, get training and employment. Empowerment is a very controversial term. Empowerment, a term commonly used by both liberal and radical feminists, means equipping women with the education, functional literacy and employable skills to challenge and free themselves from unemployment and male domination. Within the Botswana context, empowerment, on paper, means using the political, social, economic and educational weapons to bring changes (Presidential Task Group, 1997; Ministry of Finance and Development Planning, 1997).

\section{Limitations of the Women's Empowerment Approach}

The women' literacy and empowerment approach is limited because it will not cover dimensions of deficiency not detectable by literacy and empowerment analysis. Literacy programs in the Third World Programs tend to be based on the system of the former European country or colonizer. Since the 1960s and 1970s, promotion of literacy as a source of empowerment among women remained a major target for colonial and postcolonial African governments. This is true of Botswana where functional literacy programs are modelled along the British educational system and are not necessarily a response to the needs of Botswana's economy. Although Third World-based studies indicate that income and employment opportunities are limited for semi-literate and non-literate women, literacy alone is not a factor in lack of power, income and employment opportunities.

Patriarchal African societies promote male domination. Mohanty, (1991b) actually lashes out at Western scholars for misinterpreting and underestimating the abilities and roles of African women. African women see and address issues in terms of how they relate to their lives and surroundings. Education, and especially women's literacy, is generally perceived to be an important source for empowering women to question societal structures that oppress them. Feminist concerns include indirect, long-term strategies that aim at uprooting the root causes of gender disparities, which is a result of discrimination against women. The workshop methodology as articulated below gave women an opportunity to articulate practical experiences of working as a collective as Women's founders. Their deliberations as indicated in the discussion, were consistent with theoretical constructs articulated in the combined gender and feminist framework.

\section{Participatory Methodology}

The one day workshop was intensive and highly participatory, providing a supportive learning environment for exchange of experiences merged with technical depth, strategy development and skill building. The workshop used group plenary discussions, and focus breakaway groups sessions. The workshop offered technical knowledge on the need for training, mentorship, transition and transformation of Women Founders with a special focus on the need for the Women's Affairs Department (WAD) to design training programmes to empower women. WAD is also vested with the mandate to highlight, through training programmes and workshops, successful approaches to implement that National Gender Framework, redress gender inequality, strategise on HIV prevention, voluntary counseling and testing, care and support, and prevention for People living with HIV. Some of the tools used during the workshop were:

- Group discussion

- Audio visual presentation

- Participatory exercises

- Case studies

- Role plays

\section{Findings and Discussion}

Gender balancing through Gender and Development

\section{Transition from Women in Development (WID) to Gender and Development (GD)}

Different women founders and feminist actors present at the workshop said they advocated the WID and the GD approaches to development and Botswana is not an exception. The WID characterized by intent to address constraints and assist women to be economically empowered by giving them an opportunity to access resources to earn or obtain a source of livelihood was the first to be implemented by the Women's Affairs Department (WAD). Critiques of this approach contend that even with a certain amount of education, funding and training, 
there are socio-cultural barriers that militate against women's employment and progression at the workplace.

Having identified loopholes within the WID approach, WAD and other actors who were part of women's founders made a transition by moving away from the WID to Gender and Development (GD) as a broader way of conceiving the root causes of women's plight and addressing them in a holistic way by looking at the relationship between men and women. It is important to note that the Government of Botswana, through the WAD originally applied the WID approach. It was found to have many shortcomings that made it difficult for advocates to make a meaningful change in the issues of women's status. The GD approach was then adopted. However, despite these commendable efforts, unpaid NGO work has remained a woman's province not only in Botswana but globally.

Botswana as a nation has visions and slogans articulated through ratification of international instruments and accords. Within these visions and slogans is the notion to portray a commitment to promoting gender equity by implementing the Dakar/NGO Declaration and the SADC Protocol on Gender and Development, with a focus on five areas specific to redressing gender issues.

\section{1) Promotion of Gender Equality}

Botswana has adopted the women in development, Convention on Elimination of all forms of Discrimination Against Women (CEDAW) in 1996, and endorsed the SADC Declaration on Gender and Development in 1997. These are milestones that typified on national recognition to promote gender equality.

\section{2) Amendment of National Laws Which Affect the Rights of Women}

In addition to promoting gender equality, Botswana embarked on national laws which affect the rights of women. Such laws include the public service Act Affiliation Proceeding Amendment Act of 1999, Penal code amendment Act of 1997, Deeds Registry Amendment act 1996, Employment Act of 1996 and the Citizenship Act of 1995.

\section{3) Provision of Basic Education for the Girl Child}

There is gender equality in access to education at primary and secondary levels. At primary and Junior Secondary, levels, girls participation is favorable but boys predominate at senior secondary school and tertiary levels where there are disparities. There are gender differentials in secondary level such that females are still left behind in access to different levels of vocational education. They are concentrated in education, humanities and social sciences while males are relatively higher in engineering and science. Access to knowledge through education serves as a social vaccine which gives opportunities to protect the youth from HIV/AIDS and other preventable fatal infections and illnesses.

\section{4) Increasing Participation and Contribution of Women to Sustainable Development}

Women have contributed to economic activities that promote sustainable development though their contribution is under reported, partly because they do a lot of unpaid rather than paid work.

\section{Male Participation}

There is also a concern that gender can be substituted for "woman" because of its tendency of gender issues and activism to attract more females than males. There is an identified need to interrogate aspects of culture that trample on human rights in order to cultivate culturally sensitive approaches. The call for male participation in the reproductive health and household activities has increased since 1990 through the nation's health and reproductive Health Programme and youth action plan.

Legally, Botswana as a nation identified and rectified laws that discriminated against women. However, socio-cultural practices still prevail to disadvantage women in all fronts such as access to land and credit by women, youth, and ethnic minority groups. In 1992, UNICEF conducted a study of the girl child in Southern African countries of Botswana, Burundi, Ethiopia, Kenya, Madagascar, Mozambique, Rwanda, and Somalia. A synthesis report indicates problems of conditions of learning and curriculum, enrolment, retention, achievement and child labor. Firstly, the schooling context on figures for boys and girls were reported high. There has been tremendous increase since independence. Repetition and wastage rates are reported high. Drop-out rate for girls is higher than that of boys in Botswana.

Since the mid 1990s, UNICEF as an organization striving for gender parity has conducted empirical studies in an effort to accelerate progress on girls' education in the Eastern and Southern African regions. The first phase of the study was done in 1996-2000. The eight countries that participated are Botswana, Eritrea, Ethiopia, Namibia, South Africa, Swaziland, Uganda and Zimbabwe. The first phase of the study identified disparities and constraints in access to general education by the girl child. Lack of knowledge that counts is often identified with educational disadvantage of the girl child. 
Indeed the global monetary economy is dependant on women's charity work within the NGO sector, reproductive and care-giving work for the health, well-being and indeed the very existence of the paid work force. The economy also relies heavily on women to pick up the slack which the paid economy ignores - nursing elderly people, tutoring, child care, and supporting new immigrants. Unpaid work, though unjustly treated, is as much a part of the monetary economy as paid work. Yet precisely because it is unpaid, unpaid work has long been overlooked and undermined in economic equations. Sometimes even those who perform unpaid work regard themselves as "not working" and thus even forget that unpaid work is actually work. The other side of the coin regarding the pride in celebration of 100 years of paid and unpaid work is that there are also hazards often associated with unpaid work in particular.

\section{Understanding the Key Concepts}

After presentations by the facilitators, women dialoged about the practical concepts of training, mentorship, transition and transformation.

\section{Training}

There was an agreement that training means the acquisition of skills, positive attitudes, skills and best practice for women founders to function during and after the transition and transformation periods. Firstly, women need training in leadership and other aspects of the mandate of organizations if they are expected to be effective and efficient in their organizations. Men also need training if they are expected to function effectively as Chief Executive officers of NGOs rather than expect to be placed by notions of masculinity.

\section{Mentorship}

During the interactive discussion sessions, it was observed by women that mentorship is about grooming, and letting go, off the organization. Taking over the Organization, and letting it go after building it up are often very difficult processes. Even with Botswana Football Association (BFA) where men are key actors, it is always difficult for mentors to let go. A report on Botswana's Guardian Newspaper of last week (10 ${ }^{\text {th }}$ August 2012) contains saddening news about how the Botswana Olympic competitor ended up in position four because her coach did not go for the Olympics. The Minister of Youth, Sport and Culture and other stakeholder, who are mainly men, have to this date not given any explanation of how Botswana lost the much awaited medal possibly because of lack of coaching by whoever was supposed to accompany the athlete. Ongoing Talk shows over both broadcasting and print media are sheer expressions of anger over the loss that nobody can undo, hence mentorship under siege. It is not clear if a satisfactory explanation will unfold as investigations and nation- wide evaluations of the entire omission unfold.

Secondly, after training, women need to be mentored by older women in the oragnisation, work together through a transition period, and be transformed if they are expected to bring about transformation to the organizations and other women with whom they work.

Sometimes women have to form another $\mathrm{NGO}(\mathrm{s})$ after leaving the first one because it becomes difficult for them to let go completely.

Thirdly, women further illuminated that while mentorship was important, it is usually very difficult for women to get together as Women's founders because of problems of competition, rivalry, status, class, ethnicity, educational attainment and all aspects of human nature.

\section{Transition and Transformation}

Women agreed that, for a smooth transition and transformation, it is better to get rid of grudges by talking over problems, and start on a clean slate with whoever women happened to begrudge. For the sake of progress, grudges and petty jealousies must be removed. Women's founders need transition and transformation to grow big and global in the sense by attracting everyone who is or interested in being a Women's founder.

Barriers Against working together as Women

\section{Leadership Crises}

Leadership for most women is a big problem. In almost the NGOs like Christian women's fellowship, NGO Coalition and other affiliates of Botswana Council of Non Governmental Organizations (BOCONGO), there is usually a fight for lime- light exposure. Women want to wear hats everywhere and those few serve as board members for all NGOs. Young women can't find space; hence they remain at the mercy of relatively older women. There isn't enough exposure to a large number of women during and after independence. 


\section{Misuse of Borrowed Power}

According to the Workshop participants from Botswana, women whose husbands were of status were chosen as leaders with no idea that they were not leaders in their own right. Their husbands were genuinely groomed for leadership while there was patriotism for the wives without a base. This patriotism modeled women to think they were leaders while they aware not fit to be. As a result Botswana lost talents of women who were not given a chance, for women who were groomed to subsist in borrowed power.

\section{Failure to Compromise}

According to women founders from Botswana, the process of founding an organization, mentoring and letting go is not easy. It is often difficult for the mentor and the mentee to reach an agreement on when to let go. This failure to reach an agreement may result in sidelining the mentor or the mentor sidlining the mentee by withholding information valuable for the men tee to proceed to leadership.

\section{Challenges of being a Women's Founder}

Marketing the organization and attracting enough attention and support is problematic.

Focus on relationships, contextualization of ideas, finance, complementation of programmes is big challenges that women's founders have to face.

Teething problems of managing an organization, sustainable resources: Financial and human, socio- cultural factors, political reaction, viable networks, sustenance of membership, and Letting Go are major challenges. There is often fear of the death of the organization, and lack of understanding of the process of transformation. Founders feel bonded to the organizations' objectives and therefore feel ownership of the organization.

They feel thy have to be responsible for the survival of the oragnisation.

\section{Strategic Plan/Time Frame for the Survival of the Organization}

Participants shared experiences of how younger women who took over frustrated and failed to recognize women that had contributed to the survival of organizations. There must be an appreciation of founders to make a smooth takeover is vital.

Transition and change management are very important.

Benefits of a Collective

\section{Sharing of Ideas, Resources, and Building One Another as Women}

Women can be open to new ideas and support one another regardless of socio- economic status and cultural backgrounds.

Borrowed power should be accomplished through training and capacity building so that women can acquire the skills to do what needs to be done.

Women founders agreed that there was a need to work together and share resources as a collective. Trasnition and transformation are required for NGOs to go through change.

In a collective, everyone takes a piece of it. Be part of a collective and not regard yourself as an individual. Ownership of an NGO is shared by everyone. The Setswana proverb that: "Letlhaku le lesha le agelwa mo go le legologolo" (Translated as: the collective aspects need to build on what is already in existence) is true that there is a need to build on what is there. Botswana has a lot of achievements in Women as founders. (Modie-Moroka \& Raditloaneng, March, 2008)

\section{Transition and Transformation}

Transition is a process of adaptation to what has already happened. Adaptation is developmental, relational (must shift in form) and situational since the Beijing conference. Transition requires an institutional path, and time. Transformation is about change of the better. There may be a requirement to change physically, structurally or ideologically after going through a transition. For instance, in Botswana there was a gradual transition from the Women in Development (WID) to the Gender and Development (GAD).

Change may also be revolutionary and entail a total makeover by the death of what was before. The old game may not be applicable and can be dropped in favor of the new one. This usually would cause vengeance and lack of trust among women. What is important is that women should not lose each other during transition and transformation. There is a need for inclusiveness, humility and reconceptualisation. 
Leadership is about speaking, listening and taking appropriate action. Women are all women. They need to work together and bring each other on board. It is important to hold a dialogue with people, rather than trying to educate or develop them. Major setbacks/ challenges included lack of finance time keeping and lime lighting, articulating the focus of an Organization and Strategic Plans and unreasonable expectations and practices were identified as major setbacks.

\section{Implications for Training on Gender and Development in Botswana}

Through the Women's Affairs department (WAD), it was important to sit back and make decisions on how to revive the whole concept of women's founders, with a special focus on those that were left behind with regard to the Gender and Development Approach (GAD), and training on acquisition of leadership skills (The National Gender Framework,1998). For effective the processes of training, mentorship, transition and transformation, it is important for leaders to segregate target groups for training, mentoring, and sensitization programmes by geographical location, places of residence, occupation, and other identifiable characteristics.

While the focus of this paper is on the need for training, mentorship, transition and transformation, these should be done cognizant o the fact that these are not magic solutions to the problems of non- performance by Women's Founders. They are only relevant if inadequate performance in leadership and women's movement are due to deficiencies in training, mentorship, transition and transformation.

Using the lenses of gender and a feminist standpoint, Women's Founders collective as a social movement must be inclusive of interested men and boys where they are available. All actors must be wiling to go of training. Mentorship, and serve as part of the processes of transition and transformation.

\section{Recommendations}

Participants from the USA and Botswana agreed to plan for a conference to bring together all women founders and their supporters together and form a powerful collective.

Participants agreed that women as founders need training to acquire the skills, positive attitudes, and skills to do their work effectively and efficiently. Women need to be made to recognize their abilities, and appreciate that not all of them are equally equipped to be leaders at the same time. There is a chance for everyone to be mentored during different phases of the life of an organization.

Transition and transformation have teething problems that need to be addressed by committed Women Founders to ensure that all women, and men willing to work amongst women, both mentees and mentors are on board to promote best practice.

Training on Gender and development (GAD)need to be inclusive of both men and women in adulthood, girls and boys in childhood so that gender issues, HIV and AIDS as gender- based programmes and problems are not perceived as issues only for the women's agenda.

Based on the above, it is recommended that:

There is a need to have knowledge if men and women are expected to fully participate in democratic governance for gender equality. This includes participation in training, mentorship, transition and transformation. Knowledge can be used for making structures of governance gender responsive. There is feminization of poverty because of lack of access to knowledge that can give women an opportunity to reduce poverty.

Economic, trade and labor policies such as scarce skill allowance have different effects on men and women due to unequal treatment and access to knowledge. There is a need for gender activists to participate fully mobilize others to maximize participation.

Official statistics must devote a section or special reports on NGO unpaid work so that it is officially recognised rather than discarded as "not worthwhile" just because it is not remunerated in the form of cash. With donor fatigue, many NGOs gradually close because of lack of funds. Women as key actors remain in the lurch. In a similar way as annual reports in different countries indicate "Who is who... The year that was...." and all the columns that command celebrities of paid NGO work and promotions, there must be a concerted effort in terms of a political will to reward and document success stories in unpaid work done by NGOs actors who are mainly women. 


\section{References}

Botswana Government/UN. (Aug. 1998). National Gender Programme Framework. Gaborone: The UN/Botswana Government.

Botswana Society. (1997). Poverty and plenty- The Botswana Experience. Gaborone: Botswana Society.

Chilisa, B. (1998). Gender, access and equity in basic education. Paper presented at the seminar on Gender, Education and Culture (pp. 12-15).

Dow U., \& Kidd, P. (1994). Women, Marriage and inheritance. Gaborone: Women and the Law in Southern Africa Trust.

Freire, P. (1970). Education for Critical Consciousness. New York: Continuum Publishing Company.

Hooks, B. (1984). Feminist Theory from margin to center. Boston: South End Press.

Jagger A. M., \& Rothenberg, P. S. (1993). Feminist Frameworks: Alternative theoretical Accounts of the Relations between men and women ( ${ }^{\text {rd }}$. Ed.). New York: Mc Graw-Hill, Inc.

Mama, A. (1997). Sheroes and villains: Conceptualizing colonial and contemporary violence against women in Africa. In Alexander, M. J., \& Mohanty, C. T. (Ed.), Feminist genealogies, colonial legacies, democratic futures (pp. 42-62). New York: Routledge.

Mannathoko, C. (1992). Feminist theories and the study of gender in Southern Africa. In R. Meena (Ed.), Gender in Southern Africa: Conceptual and Theoretical Issues. Harare: SAPES Trust.

Mbilinyi, M. (1996). Towards a Transformative methodology of political economy in adult education: A critical Third World Feminist Perspective. In P. Wongoola, \& F. Youngman (Eds.), Transformative political economy of adult education (pp. 33-69). Dekalb. LEPS Press.

Meena, R. (Ed.). (1992). Gender in Southern Africa: Conceptual and Theoretical Issues. Harare: SAPES Trust.

Ministry of Finance and Development Planning. (1997). National Development Plan 8, 1997-2002/2003. Gaborone: Government Printer.

Modie-Moroka. (March 20, 2008). Transition and Transformation in WAD. Paper presented at the Women's Founders' Collective meeting. Gaborone: Women's' Affairs Department Committee Room.

Mohanty, C. T. (1991b). Cartographies of Struggle: Third World women and the politics of feminism. In C. T Mohanty., A. Russon, \& T. Lourdes (Eds.), Third World women and the politics of feminism (pp. 51-80). Bloomington, IN. Indiana.

Presidential Task Group on a Long Term Vision for Botswana-Towards Prosperity for All. (1997). A Long Term Vision for Botswana- Towards Prosperity for All. Gaborone: Presidential Task Group.

Raditloaneng, W. N. (March 20, 2008). Mentorship in WAD. Paper Presented at the Women's Founders' Collective meeting. Gaborone: Women's' Affairs Department Committee Room.

Stefanos. (1997). African Women and revolutionary change: A Freirian and Feminist perspective. In P. Freire., et.al. (Ed), Mentoring the mentor: A critical dialogue with Paulo Freire (pp. 243-271). New York: Peter Lang.

Tisdell, E. J. (1993). Feminism and adult learning: power pedagogy and praxis. In S. B. Merriam (Ed.), An update on adult learning theory (Number 57, spring 1993) (pp. 91-103). New Directions for Adult and Continuing Education. San Francisco: Jossey Bass.

Tong, R. (1989). Feminist Thought: A comprehensive guide. Boulder, CO: West view Press. www.womensfounders.org 